\title{
Freud, Lacan e Laclau: o entroncamento ardiloso entre discurso, pulsão e gozo ${ }^{1}$
}

Freud, Lacan and Laclau: The artful intersection between discourse, drive and jouissance

\section{Alexandre Starnino*}

Resumo: A concepção lacaniana de sujeito cindido e descentrado e suas consequências, implicada à linguagem e ao discurso, subverteu radicalmente significativa parte do campo de estudos concernentes à discursividade. Podemos inscrever a destacada Teoria do Discurso de Ernesto Laclau como um aprofundamento dessa subversão lacaniana, incorporada a uma abrangente investigação dos processos sociopolíticos e identitários. No presente artigo, promovemos uma analítica das implicações teóricas do dispositivo psicanalítico presentes em sua Teoria do Discurso a partir de três direções: (A) os pressupostos de 'irredutibilidade do sentido' e a 'lógica do significante' como ponto de partida; (B) e a implicação da categoria 'sujeito cindido e descentrado' impostos a fundamentação do campo do discurso 'para além das áreas da fala ou da escrita'; (C) O terceiro eixo, o mais explorado, articulamos a relação teórica entre 'discurso, campo pulsional e o gozo (la juissance)', repensado por Laclau nos limites e consequências do político. Por fim, propomos algumas formalizações como forma de demonstrar o jogo teórico explicitado.

Palavras-chave: Teoria do discurso; Gozo; Pulsão; Ernesto Laclau; Jacques Lacan; Freud

Abstract: The Lacanian conception of a split and decentered subject and its consequences, implicated in language and discourse, radically subverted a significant part of the field of studies concerning discursiveness. We can inscribe Ernesto Laclau's outstanding Theory of Discourse as a deepening of this Lacanian subversion, incorporated into a comprehensive investigation of socio-political and identity processes. In this article, we promote an analysis of the theoretical implications of the psychoanalytic device present in his Theory of Discourse from three directions: (A) the assumptions of 'irreducibility of meaning' and 'logic of the signifier' as a starting point; (B) and the implication of the category 'split and decentralized subject' imposed on the grounding of the field of discourse 'beyond the areas of speech or writing'; (C) The third axis, the most explored, articulates the theoretical relationship between 'discourse, pulsional field and enjoyment (la juissance)', rethought by Laclau in the limits and consequences of the political. Finally, we propose some formalizations as a way to demonstrate the explicit theoretical game.

Keywords: Discourse Theory; Enjoyment; Pulsation; Ernesto Laclau; Jacques Lacan; Freud

\footnotetext{
${ }^{1} \mathrm{O}$ presente artigo se relaciona com parte de sua dissertação de mestrado intitulada: Entre o couro e a carne: Jacques Lacan e a questão da identidade e identificação, UNICAMP-2018; e com as novas pesquisas em andamento na Unicamp com apoio da FAPESP (2019/00407-0). Agradeço imensamente ao Professor Dr. Daniel Omar Perez pela grande influência e diálogo continuo em torno do problema aqui discutido.
}

\footnotetext{
Doutorando em Filosofia na Universidade Estadual de Campinas, Campinas, SP. E-mail: alexandrestarnino@hotmail.com ORCID: https://orcid.org/0000-0001-5876-1820
} 
Nada é mais candente do que aquilo que, do discurso, faz referência ao gozo. O discurso, faz referência ao gozo. O discurso toca nisso sem cessar, posto que é dali que ele se origina (...). Saibam que o gozo é o tonel das Danaides, e que uma vez que ali se entra não se sabe onde isso vai dar. Começam com as cócegas e termina com labaredas de gasolina. Tudo isso é, sempre, o gozo.

LACAN, Seminário XVI

\section{Introdução e caminhos}

Um dos pilares da conhecida Teoria do Discurso de Ernesto Laclau germina dos pressupostos psicanalíticos impostos ao amplo campo de estudos do discurso e da linguagem. Analisar os elementos teóricos centrais derivados da psicanálise freudolacaniana que dão corpo a referida Teoria do Discurso é o que está em jogo em sentido amplo nesse artigo. A título de introdução dos caminhos aqui trilhados, podemos estabelecer três eixos que fazem parte do que chamamos de 'consequências psicanalíticas' incorporados por Laclau e aqui analisadas:

(a) A 'irredutibilidade do sentido' imposta à formação da significação discursiva, rompendo com a "lógica simbólica". A Psicanálise insere na "natureza do pensamento reflexivo o princípio de uma lógica do duplo sentido, complexa e não arbitrária, rigorosa em suas articulações, mas irredutível à linearidade da lógica simbólica”2;

(b) Esse rompimento é derivado necessariamente da implicação da categoria 'sujeito cindido e descentrado' e suas 'condições de enunciação’;

(c) O terceiro e principal eixo trata-se da complexa imbricação teórica entre 'gozo, pulsão e discurso', proposto inicialmente por Jacques Lacan.

Esses três eixos são analisados no artigo de modo intercalado sendo mais evidenciado o terceiro eixo, por ser precisamente, conforme veremos, o ponto de maior avanço epistemológico do empreendimento teórico proposto por Ernesto Laclau.

\footnotetext{
${ }^{2}$ RICOEUR, De L'interprétation, Essai Sur Freud p. 56. Sobre isso, Jardim nos diz: "O a priori desta lógica transcendental, contudo, não é o a priori kantiano. Trata-se, antes, dos "signos esparsos na cultura", do universo simbólico, portanto, "de um novo campo de experiência, de objetividade e de realidade", distinto daquele pensado pela filosofia de Kant (cf. RICOEUR, De L'interprétation, Essai Sur Freud, p. 52). Em síntese: a linguagem ambígua, as expressões equívocas e metafóricas estão aí, no que Husserl denominou “mundo da vida”. A lógica formal não é capaz de pensá-las. Urge, então, recorrer a outra lógica, isto é, à lógica do duplo [múltiplo] sentido (...) para resgatar a linguagem cotidiana, ou seja, em termos kantianos, para investigar as condições de possibilidade de uma tal linguagem” (JARDIM, Energética e Hermenêutica, p.162).
} 
Primeiramente, começamos pelos dois primeiros eixos ao abordar introdutoriamente no que consiste a Teoria do Discurso de Ernesto Laclau, enfatizando as raízes e efeitos impostos pelo campo psicanalítico a sua teoria; especialmente pela influência de Jacques Lacan. O texto privilegiado nesse momento é uma das últimas obras publicadas por Laclau, A Razão Populista, obra que em certa medida se tornou a síntese de seus trabalhos anteriores. Os seminários lacanianos também são referenciados nesse momento; principalmente o Seminário VII - A Ética da Psicanálise, Seminário IX - A Identificação e o Seminário XX - Mais Ainda.

Num segundo momento, procuramos estabelecer as relações entre discurso, campo pulsional e gozo (la jouissance), articulando as consequências do que Ernesto Laclau denomina de "investimento radical", a partir da inserção do gozo no "campo dos afetos".

É preciso ressaltar as dificuldades teóricas, algo que talvez seja evidenciado no artigo, ao estabelecer o espaço conceitual comum entre a discursividade, o gozo, as pulsões e o corpo social onde isso se constrói e se estabelece, por se tratar de uma intersecção conceitual atravessada por matrizes conceituais então distintas; levando em conta, é claro, a maneira engenhosa e inovadora com que Laclau as dispõe em sua Teoria do Discurso.

O ponto mais crítico em termos conceituais é a aproximação, amparada em Lacan, que Laclau articula da noção de gozo vinculada a afetividade; obviamente não livre de possíveis críticas no interior do lacanismo. "O afeto, isto é, o gozo, é a própria essência do investimento [pulsional]”, afirma. Delimitar isso se torna inequivocamente o ponto alto desse artigo. Por isso, dispendemos mais tempo no percurso do nosso texto até chegar a essa precisa formulação, inclusive propomos algumas formalizações como forma de demonstrar o jogo teórico explicitado.

\section{A Psicanálise e a Teoria do Discurso de Ernesto Laclau}

\section{(A) A irredutibilidade do sentido}

O campo do saber psicanalítico se abriga num dizer que excede o dito. A Psicanálise pode ser entendida como um saber que se articula desde as entranhas da enunciação. Seja na dimensão da clínica ou como ferramenta teórica para compreender os fenômenos que atravessam o campo sócio cultural e político, a articulação de conceitos psicanalíticos se estabelece não nos trilhos do que está posto na primazia do enunciado, mas antes se abriga nas malhas do discurso, por assim dizer, excedendo e transbordando o

\footnotetext{
${ }^{3}$ LACLAU, A Razão Populista, p. 179
} 
enunciado; ampliando o campo de sentido desde o horizonte de um suposto sujeito e de suas condições de enunciação ${ }^{4}$.

Jacques Lacan em seu terceiro seminário afirmou, justamente, que a Psicanálise poderia ser definida como "a ciência da linguagem habitada pelo sujeito" 5 . Como nos diz Milner, os “'jogos de língua’ (...) só interessam à Psicanálise na medida em que marcam a emergência de um sujeito - somente daí nascem os efeitos de sentido que eles operam”. Essa relação tensa entre Psicanálise e o fenômeno da linguagem "se coloca desde os primeiros trabalhos de Freud"6. Conforme nos apontou Ricoeur, "é no campo da palavra que a experiência analítica se desenrola e que, no interior desse campo, o que se evidencia é uma outra linguagem, dissociada da linguagem comum e que se deixa decifrar através de seus efeitos de sentido: sintoma, sonhos, formações diversas, etc. (...)"7. Disso resulta a afirmação de Lacan no Seminário $I X$ de que ao articular "uma lógica do funcionamento do significante" se explora justamente "remessas infindáveis de sentido" 8 .

O pressuposto psicanalítico de irredutibilidade do sentido é o que proporciona no dizer de Lacan "remessas infindáveis de sentido". Segundo Ernesto Laclau, esse é “o processo que a Psicanálise explora essencialmente" 9 . Para sua Teoria do Discurso, o autor enfatiza "o fato de que esse processo de associação [entre significado e significante] não opera unicamente no nível gramatical - nível primariamente estudado por Saussure - mas também em nível semântico" ${ }^{0}$. Deste modo, "ambos os níveis se cruzam constantemente e conduzem a associações que podem avançar em diversas direções" ${ }^{11}$.

Esse “avançar em diversas direções” aludido por Laclau, proveniente do processo de exploração psicanalítica da não redutibilidade do sentido vigente na tessitura da linguagem e discurso, só se consuma na conformação tácita de que a formação associativa do significado é gregária necessariamente das condições contingenciais da origem da enunciação - isto é, do sujeito que a enuncia -, e por isso capaz de atingir "remessas infindáveis de sentido" ${ }^{12}$; em níveis que se cruzam 'do semântico ao gramatical'.

Em termos mais práticos, um exemplo do campo político privilegiado por Laclau ilustra bem o que estamos apontando:

\footnotetext{
4 Sobre as noções de enunciado e enunciação ver STARNINO, Sobre Identidade e identificação em Psicanálise

${ }^{5}$ LACAN, O Seminário Psicoses. Livro 3, p. 276

${ }^{6}$ MILNER, Linguística E Psicanálise, p.7

${ }^{7}$ RICOEUR, De L'interprétation, Essai Sur Freud, p. 297

${ }^{8}$ LACAN, O seminário, Livro 9, p.149 e p.34.

${ }^{9}$ LACLAU, A Razão Populista, p. 60-62

${ }^{10}$ LACLAU, A Razão Populista, p. 60-62

${ }^{11}$ Ibidem.

${ }^{12}$ LACAN, O seminário, Livro 9, p.149 e p.34.
} 
o significante trabalhadores em certas configurações discursivas pode exaurir-se num significado particularista, setorial, enquanto que em outros discursos - o peronista por exemplo - pode-se tornar o nome par excellence do 'povo' (...). Nenhum conteúdo particular traz inscrito em sua especificidade ôntica seu significado numa formação discursiva ${ }^{13}$.

O significante trabalhadores para um peronista (sujeito da enunciação) não se confunde com o significado ora enunciado, por exemplo, por um chefe de recursos humanos de uma multinacional. Os entes, no caso aí os 'trabalhadores argentinos', não carregam em sua especificidade mundana a significação anterior ao "jogo de linguagem"14 estabelecido. O peronista indaga pelo 'povo' quando anuncia o significante trabalhadores.

$\mathrm{Na}$ visada proposta por Laclau, o significado dependente em última instância do sujeito e de suas condições de enunciação. Ao endossar a essa, digamos, determinação psicanalítica de impossibilidade de um "verdadeiro significado" 15 e "remessas infindáveis de sentido"16 (ou 'irredutibilidade do sentido'), afastando-se definitivamente de um positivismo lógico, Laclau engendra nas bases de sua Teoria do Discurso um dos fundamentos centrais da prática clínica; agora incorporados e aplicados na análise das mais diversas construções discursivas, sobretudo no que remete a um aprofundado estudo "da lógica e formação das identidades coletivas"17 e constituição do "fenômeno do populismo"18, tema proposto em primeiro plano pelo autor em A Razão populista.

Não é a palavra que pode fundar o significante. A palavra não tem outro ponto onde fazer-se coleção senão no dicionário onde ela pode ser alistada”

Ao definir sua Teoria do Discurso, Laclau afirma ser da ordem do campo discursivo,

\footnotetext{
${ }^{13}$ LACLAU, A Razão Populista, p.141.

14 "Jogos de linguagem" (Sprachspiel), termo de Wittgenstein apropriado por Ernesto Laclau.

${ }^{15}$ LACLAU, A Razão Populista, p. 60

${ }^{16}$ LACAN, O seminário, Livro 9, p.149 e p.34.

17 Em Entre o couro e a carne: Jacques Lacan e a questão da identidade e identificação, procuramos estabelecer a estrutura e a lógica da formação das identidades e identificações coletivas numa interlocução com, sobretudo, Ernesto Laclau e Jacques Lacan

${ }^{18} \mathrm{O}$ populismo é um tema que atravessa todo percurso teórico de Laclau. No entanto, uma discussão mais profundamente articulada encontramos em $A$ razão populista. O próprio título da obra já revelaria que há uma racionalidade política, histórica e identitária no interior da constituição do populismo. Laclau irá dedicar toda a primeira parte da respectiva obra para criticar as leituras que apontam o populismo como sendo algo da ordem do irracional.
} 
algo que não é essencialmente relativo às áreas da fala e da escrita, mas quaisquer conjuntos de elementos nos quais as relações desempenham o papel constitutivo. Isso significa que os elementos não preexistem ao complexo relacional, mas se constituem através dele. Assim, relação e objetividade são sinônimos. Saussure afirmou que não existem termos positivos na linguagem, mas unicamente diferenças - uma coisa é o que é somente por meio de suas relações diferenciais com outras coisas. E aquilo que é verdadeiro em relação à linguagem concebida em estrito sensu é também verdadeiro em relação a qualquer elemento significativo (isto é, objetivo): uma ação é aquilo que é somente através de suas diferenças relativas a outras ações possíveis e a outros elementos - palavras ou ações que podem ser sucessivos ou simultâneos (...). Tornou-se possível ir além da subjugação de Saussure às substancias fônicas e conceituais e desenvolver as implicações ontológicas desse avanço fundamental: toda referência linguística puramente especifica foi, em grande medida, abandonada ${ }^{19}$.

Laclau vai expandir o campo do discurso e estabelecer que qualquer "elemento diferencial" contingencialmente articulado com outros "elementos diferenciais" são passíveis de significação; o que na verdade é uma retomada do que Lacan promove ao não circunscrever o significante unicamente ao "suporte fonemático" ${ }^{20}$, tampouco estritamente a palavra ${ }^{21}$. Numa definição feliz, Colette Soler nos diz que por significante podemos denominar "todo elemento discreto, isolado e combinado a outros elementos igualmente discretos e isolados, suscetíveis de serem tomados por um sentido ou significado’22.

Dito de outro modo: um ato político qualquer, numa manifestação pública qualquer, "pode ser um significante, desde que entre em uma estrutura combinatória de representações” ${ }^{23}$. É extremamente significativo, por exemplo, 'queimar a bandeira' do partido adversário em praça pública; a força afetiva desse ato estabelece laços identitários. Conforme nos mostrou Laclau, no trecho acima, uma ação é um elemento significante, e se articula enquanto discurso na relação diferencial com outros significantes e outros discursos. Inclusive antagonizando, muitas vezes, em sua significação, ainda que partindo de um mesmo significante: A mesma "bandeira queimada" é motivo de ódio aos partidários e, por outro lado, de volúpia para os adversários agentes do ato.

\footnotetext{
${ }^{19}$ LACLAU, A Razão Populista, p.116

${ }^{20}$ Lacan nos diz: "o significante não pode limitar-se de modo algum ao suporte fonemático, (...) [tampouco] é a palavra que pode fundar o significante” (LACAN, O seminário, Livro 20, p.29). Em outro lugar, Lacan irá afirmar que o "significante falado" é só um dos modos de sua encarnação". (Cf. LACAN, O seminário, Livro 9, p. 325)

${ }^{21}$ No original: "não é a palavra que pode fundar o significante. A palavra não tem outro ponto onde fazer-se coleção senão no dicionário onde ela pode ser alistada” (LACAN, O seminário, Livro 20, p.29).

${ }^{22}$ SOLER, Ce que Lacan disait des femmes, p.53 (tradução e grifos nossos).

${ }^{23}$ Ibidem
} 
Ao incorporar em primeiro plano a lógica lacaniana do significante, a Teoria do Discurso de Laclau "captura a ideia de que todos os objetos e ações são significativos, e que seus significados são conferidos por sistemas particulares de diferenças significativas”24. Sistemas particulares diferenciais onde a relação que compõem a cadeia (S1,S2,S3,S4...) é a condição de possibilidade da constituição da significação e, consequentemente, do laço social e identitário estabelecido.

Trabalhadores (S1) dito por um peronista é 'povo' (S1..S2,S3...); não 'os assalariados da empresa X’ (S1..S4,S5...), como seria para outro sujeito ou grupo em outra condição de enunciação, noutro sistema de diferenças.

\section{(C) O significante vazio e as cadeias de equivalência: discurso e laço social}

É preciso colocar em maior relevo, apontarmos a especificidade, a função e primazia da noção de relação descrita por Laclau. Como ele diz: "as relações desempenham o papel constitutivo. Isso significa que os elementos não preexistem ao complexo relacional, mas se constituem através dele” ${ }^{25}$. A relação de significantes estabelecida determina a potencialidade do discurso, a capacidade de gerar laços sociais, discursos hegemônicos, identidades coletivas. A relação é sinônimo para Laclau do próprio processo de constituição da significação. Como compreender esse processo? Em que limites e registro ocorre?

O processo relacional tem por condição de possibilidade a impossibilidade de um uso acabado do significante, devido ao 'vazio, negatividade e opacidade' do próprio manejo significante. Quer dizer, um significante fora da relação com outros significantes, como sabemos, é vazio. A significação se funda nos reenvios de significantes a significantes; não existem discursos, grupos identitários "definidos anteriormente ao processo de articulação e de decisão que constitui os sujeitos" ${ }^{26}$. O quanto esse campo de luta pela 'hegemonia da significação' rasga o campo social e político é demonstrado por Laclau em diversos momentos da obra A Razão Populista, e a falta de fixidez entre significante/significado, “a opacidade do processo significante" ${ }^{27}$, é condição de possibilidade da disputa pela significação hegemônica.

A falta de fixidez aponta necessariamente para "a penetração da contingência” ${ }^{28}$ nas construções discursivas: ‘irredutibilidade do sentido’. Daí resulta a afirmação de Laclau de que "o social é o lócus de uma irredutível tensão entre equivalência e diferença" 29.

\footnotetext{
${ }^{24}$ HOWARTH, Discourse, cap.VI.

${ }^{25}$ LACLAU, A Razão Populista, p.116

${ }^{26}$ LACLAU, A Razão Populista, p. 13.

${ }^{27}$ Ibidem, p. 172

${ }^{28}$ HOWARTH, Discourse, cap. VI.

${ }^{29}$ LACLAU, A Razão Populista, p.133.
} 
A noção de cadeia de equivalência articulada por Laclau é justamente a composição que gera a significação (...S1,S2,S3,S4,S5,S6...). Acerca disso, um exemplo interessante e elucidativo nos traz Howarth:

Considere, por exemplo, uma floresta que esteja no caminho de uma construção de autoestrada. Ela pode simplesmente representar um obstáculo inconveniente impedindo a rápida implementação de um novo sistema de estradas, ou ela pode ser vista como um sítio de interesse especial por cientistas e naturalistas, ou como um símbolo ameaçado da herança natural da nação. Resumindo, o sentindo de "ser" da floresta - o que ela literalmente é para nós - depende dos sistemas particulares de diferença ou discursos que constituem sua identidade. Em discursos de modernização econômica, árvores podem ser entendidas como um recurso descartável para o crescimento econômico contínuo, ou, neste exemplo, como obstáculos temporários para a construção rápida da autoestrada. Em discursos ambientalistas, pelo contrário uma floresta pode representar um ecossistema viável ou um objeto de intrínseco valor e beleza. Cada uma dessas estruturas discursivas é uma construção social e política, que estabelece um sistema de relações entre diferentes objetos e práticas, ao mesmo tempo fornecendo "posições de sujeito" com os quais agentes sociais podem se identificar. No nosso exemplo, esses sujeitos podem ser "desenvolvimentistas", "naturalistas", “ambientalistas" ou "ecoguerreiros" ${ }^{30}$.

No exemplo acima, o significante 'árvore' assume em cada cadeia um significado diferencial de acordo com o enunciador. Estabelece-se uma tensão política, onde ações, palavras e coisas se organizam numa mutua relação enquanto construções discursivas em modos de antagonismo, oposição, disputa e identidade. Em cada relação combinatória e equivalencial disposta em cadeias significantes irão residir todo o sentido e força afetiva encontrado na construção social do discurso em questão. Através da relação construída, o discurso dá a forma, as cores, o contorno, o caráter de intensidade de cada "posição de sujeito"; seja esse discurso de um único 'sujeito' ou mesmo incorporado a um 'coletivo político’. A articulação entre o vazio de cada significante compõe o rastro retroativo onde se institui a significação. Noutras palavras, o sentido se dá na objetividade da relação, e pela possibilidade do vazio negativo fundacional do significante, como já dissemos.

É preciso sublinhar que essa 'objetividade' não se trata de uma analítica tacanha onde se privilegie apenas o que aparece nos contornos do enunciado emitido pelos diversos sujeitos. Não se trata apenas desse registro. A noção de cadeia de equivalência na mesma relação teórica com o que Lacan denomina de cadeia significante - se expande para um registro onde se inclui como sentido e significação os efeitos metafóricos e

${ }^{30}$ HOWARTH, Discourse, cap.VI. 
metonímicos - o que foi elidido, negado, recalcado - na sequência de recortes que aparece na dimensão enunciativa ${ }^{31}$. Uma certa ausência que tem presença na significação ${ }^{32}$. Isso nos revela a impossibilidade de o 'acontecimento discursivo' ser algo da ordem do $s i$ mesmo na própria base de sua "estranha temporalidade"33. Daí resulta Laclau dizer, em certo sentido, que há ausências em presença. É o próprio inconsciente psicanalítico enquanto processo lacunar (béance) implicado no que aparece 'dado' numa tal linearidade discursiva. Trata-se do "um a mais” que não aparece no 'enunciado dado', mas nem por isso deixa de participar da formação de sentido e representação ${ }^{34}$.

Noutras palavras, não é só levando em conta o núcleo significante que aparece na cadeia posta no enunciado que se compreende a efetiva composição da significação, mas

${ }^{31}$ Destacamos, dentre outros, o Seminário XIV - A Lógica do Fantasma, no qual Lacan estabelece uma interessante articulação acerca da negação e a relação entre significante, discurso e formação da significação. Lacan nos diz: "Simplesmente o que constituirá essa cadeia será essa propriedade de ser um significante a mais que se constitui pelo fechamento da cadeia, um significante incontável e que justamente por esse fato, poderá ser designado por um significante. Pois não estando em nenhuma parte, não há nenhum inconveniente a que um significante surja que o designe como um significante a mais: aquele que não se apreende na cadeia [do enunciado dado]" (LACAN, O seminário, Livro 16, p.40).

${ }^{32}$ Sobre isso, Laclau nos diz: "La primera referencia es desde luego, a Heidegger, de quien la noción de "diferencia ontológica” proviene.' La categoría central es aquí la de Abgrund - un fundamento que es, a la vez, un abismo -. En el lugar del fundamento hay un abismo - o, para ser más precisos, el abismo mismo es el fundamento -. Decir que el abismo mismo es el fundamento no significa, pura y simplemente, la ausencia de fundamento, que sería una ausencia a secas, sino que sería la presencia de una ausencia. Y esta ausencia, en cuanto presencia, necesita ser representada. Una ausencia simple no requiere ningún tipo de representación; pero si la ausencia como tal está presente en el interior de la estructura, requiere tener acceso al campo de lo representable. Esta representación no puede, sin embargo, ser directa, porque lo que es representado es una ausencia; por lo tanto, solo puede ser representada como un proceso de des-fundamentación. Es aquí donde la diferencia ontológica hace su aparición: el contenido óntico no desaparece, pero es distorsionado a través de esta actividad des-fundante, si se nos permite el neologismo, que es al mismo tiempo un investimento. Y esta actividad des-fundante no es meramente negativa, sino que tiene una vertiente positiva: puesto que no hay fundamento último, no hay tampoco fijación última del sentido; pero porque este momento de nofijación debe ser representado, él abre el camino a fijaciones parciales -es decir, a fijaciones que muestran las huellas de la contingencia que las penetra, y que son el único medio de mostrar discursivamente el abismo presente en el lugar" (LACLAU, Los fundamentos retóricos de la sociedad, p.146).

${ }^{33}$ LACAN, O seminário, Livro 11, p.30. Expressão utilizada por Lacan para se referir ao inconsciente.

34 "O um a mais" é uma expressão de Lacan utilizada no Seminário XIV se referindo ao significante ausente, o um a mais, que mesmo elidido participa da significação discursiva. No Seminário IX ele irá cunhar o termo "nominação latente". No mesmo seminário XIV, Lacan vai falar em efeitos de verdade, afirmando que não se trata de falar de uma verdade sobre a interpretação, mas sim sobre "o um a mais e em excesso que se configura na articulação da significação", quer dizer, esse "um a mais" diz respeito ao(s) significante(s) que participa(m) da estrutura da significação, mas que estão elididos do enunciado posto. (Cf. LACAN, $O$ seminário, Livro 16, p.90-97) 
em função da relação contingente ${ }^{35}$ e inacabada estabelecida em sentido e registro amplo. Isso se mostrará fundamental a análise do discurso de Laclau. Por exemplo: O significante “pai protetor”, efeitos de uma fantasmagoria regressiva - 'aquele que castiga os ímpios', 'expulsa o imigrante que rouba nossos empregos', 'que nos protege dos comunistas', 'que controla a baderna, a libertinagem sexual', etc., pode muito bem estar presente "como um (ou vários) a mais" no simples estalar de duas silabas conclamando por 'Mito'”6.

Esse possível jogo fantasmático descrito acima como um dos modos que conduzem os efeitos dessa significação só funciona em sua eficácia afetiva numa comutação entre registros: o jogo não é compreendido se tomado por um olhar que privilegie apenas a imediatez do discurso enunciado conclamando pelo tal líder. O "um (ou vários) a mais" funciona como presença de várias ausências escamoteadas, elididas do mero enunciado. A noção de relação em Laclau, portanto, visa demarcar o que está amarrando e sustentando a significação, quais significantes, isto é, aquilo que garante toda a força, valor e especificidade da operação discursiva e seus efeitos (demandas, identificações, desejos, afetos, real, gozo, etc.). É a ampliação mesma do campo de analítica do discurso para além do registro do mero enunciado.

Desse modo, em Laclau é delineado a concepção de um campo da discursividade ampliado ou como ele mesmo nos diz: o "discurso enquanto tal é uma totalidade estruturada" ${ }^{37}$.

\section{Discurso, gozo e o campo pulsional}

\section{(A) Das Ding é o lugar dos Triebe: o gozo aparelhado}

Até aqui trouxemos em linhas gerais alguns dos principais conceitos da Teoria do Discurso de Ernesto Laclau, evidenciando os pontos de inflexão de pressupostos psicanalíticos incorporados às novas formas de “análise do discurso" propostas pelo autor. Nosso próximo e mais importante passo é estabelecer o ponto de maior avanço epistemológico do empreendimento teórico proposto por Laclau, a saber, a articulação entre discurso, gozo e campo pulsional.

Vejamos de início o que nos diz Yannis Stavrakakis:

\footnotetext{
${ }^{35}$ Sobre o caráter contingente do significante, Lacan nos diz: "Não estará aí o que se trata no que concerne ao significante? Isto é, que nenhum significante se produz como eterno? É aí sem dúvida que antes que qualificá-lo de arbitrário, Saussure podia ter tentado formular - o significante, melhor teria valido colocá-lo com a categoria de contingente. O significante repudia a categoria de eterno e, no entanto, singularmente, ele é por si mesmo" (LACAN, O seminário, Livro 20, p.56).

36 "Mito" foi o significante comum que se propagou em escala nacional para se referir ao presidente brasileiro eleito em 2018.

${ }^{37}$ LACLAU; MOUFFE, Hegemonía y estrategia socialista, p. 176-177.
} 
Toda tradição intelectual precisa estar em constante interação com a cena teórica mais ampla. Temos de prestar homenagem à engenhosidade de Ernesto Laclau na formulação da Teoria do Discurso de uma forma que pode incorporar muitos elementos novos e expandir-se em uma variedade de direções desafiadoras. Laclau concebeu de fato o discurso de modo a permitir o enxerto da problemática psicanalítica do real lacaniano - do afeto e do gozo - através da dialética do investimento ${ }^{38}$.

Stavrakakis reafirma a engenhosidade, o direcionamento amplo, e a inserção de elementos da Psicanálise na Teoria do Discurso de Laclau, sublinhando a questão do enxerto do Real lacaniano pela via do afeto e do gozo como fundamentais. Para esclarecer as nuances e sutilezas dessa imbricação teórica, indicamos primeiro uma interessante passagem de Lacan no Seminário VII - A Ética da Psicanálise:

O que buscamos está para além da organização do Lust-Ich, uma vez que está ligado, num caráter fenomenal, ao maior ou menor investimento do sistema das Vorstellungsrepräsentanzen, ou seja, dos elementos significantes no psiquismo. Eis algo que está aí para permitir-nos, pelo menos operacionalmente, definir o campo de Das Ding na medida em que tentamos avançar no terreno da ética. E como o pensamento de Freud progrediu a partir de um ponto de partida terapêutico, podemos tentar definir o campo do sujeito na medida em que ele não é apenas o sujeito intersubjetivo, o sujeito submetido à mediação significante, mas o que está por detrás desse sujeito? ${ }^{39}$.

O que "está por detrás do sujeito" como elemento de im-pulsão? O questionamento de Lacan pode ser lido aí como uma tentativa de elucidação acerca do estatuto radical que funda a repetição do sujeito na direção e dimensão prático discursiva; algo que se relaciona com o movimento e estatuto da pulsão ${ }^{40}$ e com o campo operacional de Das Ding ${ }^{41}$. Algo

\footnotetext{
${ }^{38}$ No original: “We have to pay tribute to Ernesto Laclau's ingenuity in formulating discourse theory in a way that can incorporate many new elements and expand in a variety of challenging directions. Laclau has indeed conceived of discourse in a way that does permit a grafting of the psychoanalytic problematic of the Lacanian Real - of affect and jouissance - through the dialectics of investment" (STAVRAKAKIS, Discourse, affect, jouissance, p.7)

${ }^{39}$ LACAN, O seminário, Livro 7, p.135, p.127 grifos nossos

${ }^{40}$ Dunker, na esteira de Lacan, irá ligar os afetos ao movimento pulsional. Ele nos diz: "poderão ser de estima para o tratamento discursivo do afeto que vimos perseguindo: Em primeiro lugar, devemos demarcar em quais termos Lacan opera - digamos, para parafraseá-lo - o que viria a ser uma 'desmontagem da pulsão'. Em detrimento de concepções que visam reduzir a essência do fenômeno pulsional aos estímulos e excitações de cunho orgânico, Lacan privilegia a sua delimitação enquanto percurso, circuito, ou ainda, traçado do ato" (DUNKER, Uma via indireta para a abordagem do afeto, p.14). Sobre isso ver também Les affects sont effects: Para pensar a noção de afeto em Jacques Lacan.
} 
que não é o significante ainda que se relacione com ele. Ora, o que 'move' o sujeito senão o gozo? O gozo se confronta e atravessa a ordem significante, está por todos os lados, mas não é Um significante. Seria algo da ordem da afecção, como propõe Ernesto Laclau?

O "menor ou maior movimento", como diz Lacan acima, na direção e relação com o sistema das “Vorstellungsrepräsentanzen (elementos significantes) ’42, se funda numa regressão absoluta de investimento radical a Das Ding. O campo de Das Ding - a Coisa -é "um campo operacional”, mítico, que aponta para um movimento repetitivo. "O que é revelado no nível de Das Ding é o lugar dos Triebe" ${ }^{43}$. O que se opera no campo de Das Ding é o próprio movimento pulsional onde o significante aparece como médium, "no âmago da tramoia humana"44.

Lacan nos aponta uma regressão radical e estrutural presente na articulação do inconsciente atemporal. Investimento naquilo que foi 'eternamente perdido' ou sequer ganho. Uma "plenitude inalcançável”, pois, "a Coisa enquanto tal não pode ser tocada diretamente em nenhum ponto sem sua representação através do objeto. Na realidade, não existe tal Coisa: é sempre uma suposição retrospectiva "45; é da ordem de um 'gesto especulativo', elementar de repetição, retroação, retrospecção.

Uma cena cinematográfica pode nos ajudar acerca do que buscamos indicar. A cena final de Holy Motors ${ }^{46}$ parece nos mostrar em imagem e som o que é a repetição, o gozo e a relação com Das Ding que nos aponta Lacan. Na respectiva cena, após um longo dia de trabalho, Oscar (Denis Levant) retorna para a sua casa, igual a qualquer outra (na cena todas são iguais). No filme de Leos Carax esse trabalho diurno exercido por Oscar se confunde com algo onírico, misturado com certas situações que parecem apontar para o caráter Real dos fatos ocorridos. As cenas de Leos Carax em Holy Motors carregam sempre o inesperado, o Real que invade e rompe o esperado. A cena toda do 'maluco' que invade o

\footnotetext{
${ }^{41}$ Como nos diz Valas (As dimensões do gozo, p.26) "Lacan irá precisar que Freud diferencia Das Ding, a Coisa, da qual não há representação, e die Sache, as coisas, que são nomeadas pelas palavras”.

${ }^{42}$ Sobre isso, Lacan nos diz: "Os investimentos nas representações são a estrutura na qual o inconsciente se organiza, a estrutura na qual a subjacência dos mecanismos inconscientes se flocula, o que constituiu o grupo de representação, ou seja, algo que tem a mesma estrutura - esse é o ponto no qual insisto - do significante. Isso não é simplesmente Vorstellung, mas, como escreve Freud mais tarde em seu artigo sobre o Inconsciente, Vorstellungsrepräsentanz, o que constitui a Vorstellung como um elemento associativo, combinatório. Desse modo, o mundo da Vorstellung é desde então organizado segundo as possibilidades do significante como tal. Desde então, no nível do inconsciente, isso se organiza segundo leis que não são forçosamente, Freud o diz mui justamente, as leis da contradição, nem as da gramática, mas as leis da condensação e do deslocamento, as que chamo, para vocês, de as leis da metáfora e metonímia” (LACAN, $O$ seminário, Livro 7, p.78).

${ }^{43}$ LACAN, O seminário, Livro 7, p.135.

${ }^{44}$ Ibidem, p.129.

${ }^{45}$ LACLAU, A Razão Populista, p. 333.

${ }^{46}$ Holy Motors. Direção: Leos Carax. Imovision, 2012. DVD (1h $55 \mathrm{~min}$ ). A cena final citada pode ser vista em: https://youtube.com/watch?v=Oq0OxtM93mk. (Acesso em 07.03.2020)
} 
cemitério comendo as flores, derrubando o paralítico, comendo o dedo da assistente do fotógrafo norte-americano, etc., representa essa quebra e súbita irrupção das 'cadeias significantes' possivelmente esperadas; evidenciando a inscrição do Real nos eventos que se passam.

Retornando à cena final em questão: Após o tal dia de trabalho, antes de adentrar a sua casa, - o suspiro. A angústia e a expectativa de Oscar são manifestas, como aquela de quem entende a necessidade de que não há saída senão adentrar, habitar aquele algo, alguma janela de realidade. Entra e diz - "Sou eu (C'est moI)". Abraça, como todos os dias, sua mulher e filho (dois primatas, que representam na cena o Real dos homens sem o simbólico, aquilo que poderia ser destinado aos homens sem a linguagem, sem o simbólico $)^{47}$. Acompanhando toda a cena a música que irá cumprir o papel fundamental de narrar todo o preciso movimento de Oscar: "O que se quer é reviver sempre a mesma coisa” e "quem sabe tocar com os dedos o ponto de não retorno”. Reviver aquilo que está eternamente perdido, na eterna esperança de tocar o ponto de plenitude do gozo: "fazer o grande percurso" 48 . Não há saída senão reviver no interior do registro da linguagem e discurso, em "objetos parciais”, qualquer coisa de uma plenitude perdida, mítica; mesmo que se hesite a cada ponto do percurso, a cada gesto, desvio, caminho e palavra, como Oscar em suas hesitações.

O gozo desse grand parcours não é confundível com o prazer. La jouissance é o modo paradoxal de satisfação da pulsão, entre prazer e dor, renúncia e transgressão, todas necessariamente implicados numa estrutura de linguagem e discurso. É o que nos diz Colette Soler a seu modo: "O que existe eminentemente é a emergência do vivente que bate à porta da - cidade do discurso - e que quando ele entra é exposto a esse gozo, afetado" ${ }^{49}$. Não há encontro possível com o gozo senão pela via do significante, das representações onde Das Ding é sempre elidida. O gozo é 'gozo na Coisa' - perturbado profundamente nessa relação - interditado em seu aceso fundamental, e só no movimento de repetição do investimento, em objetos parciais, temos um mínimo de gozo. Noutras palavras, "a medida

\footnotetext{
${ }^{47}$ Acerca disso, Lacan nos diz: "Só há inconsciente no ser falante. Nos outros, que só têm ser por serem nomeados, embora a partir do Real, há instinto, ou seja, o saber que sua sobrevivência implica. Ainda que seja apenas para nosso pensamento, talvez aqui inadequado. Sobram os animais que carecem d'homem, por isso ditos d'homésticos e que, por essa razão, são percorridos por sismos, aliás extremamente curtos, do inconsciente”. (LACAN, Televisão, p.18)

48 “On voudrait revivre. Ça veut dire : On voudrait vivre encore la même chose. Refaire peut-être encore le grand parcours. Toucher du doigt le point de non-retour. Et se sentir si loin, si loin de son enfance. En même temps qu'on a froid, quand même on pense Que si le ciel nous laisse on voudra. Revivre. Ça signifie : On voudrait vivre encore la même chose. Le temps n'ai pas venu qu'on se repose” (MANSET, Paroles et musique).

${ }^{49}$ SOLER, Les affects lacaniens, p. 77, tradução nossa.
} 
em que o gozo se define em relação à Coisa, pela dimensão do Outro como tal, enquanto essa dimensão do Outro se define pela introdução do significante" ${ }^{50}$.

Ao ser perguntado, em outra cena, o porquê do continuar: "O que te impulsa a continuar Sr. Oscar? Je continue comme je commence, pour la beauté du geste”, responde ${ }^{51}$. Não teria diferença alguma se Oscar dissesse que é pelo gozo no menor dos gestos. O caráter de desperdício e dispêndio intrínseco ao gozo, sem fim utilitário, teleológico é expresso no termo limite no menor dos gestos. Como diz Lacan, "la jouissance, c'est ce qui ne sert à rien ${ }^{52}$.

Dizendo isso, não se deve confundir a contingência com a qual se articula o gozo com a indiferença. O que se quer sublinhar é que a própria "repetição provoca o gozo, ou seja, uma motivação para agir que não se deixa calcular a partir da lógica utilitária da maximização do prazer e do afastamento do desprazer, da distinção entre alegria e tristeza" ${ }^{3}$. Do gozo "aparelhado pelo significante" ${ }^{54}$. decorre as afirmações de Lacan de que o significante é o médium que está entre a Coisa ${ }^{55}$. Um médium que intervém no próprio gozo, inclusive nos atos ditos sublimados, o gozo está ali articulado:

A sublimação, no discurso de Freud, é inseparável de uma contradição, ou seja, que o gozo, a perspectiva do que gozo subsiste e é, num certo sentido, realizado em toda atividade de sublimação. Que não há recalcamento, que não há apagamento, que não há sequer compromisso com o gozo, que há paradoxo, que há desvio, que é pelos caminhos aparentemente contrários ao gozo que o gozo é obtido. Isso só é propriamente pensável porquanto, no gozo, o médium, que intervém, médium por onde é dado acesso a seu fundo

\footnotetext{
${ }^{50}$ É o que Lacan nos diz: "Tudo isso, esses rodeios, esse caminho ladrilhado com as 'flores de Tarbes' precisamente, ou com as flores literárias, para lhes marcar bem o que quero dizer, quando falo do que acentuei para vocês: a saber, a perturbação profunda do gozo, na medida em que o gozo se define em relação à Coisa, pela dimensão do Outro como tal, enquanto que essa dimensão do Outro se define pela introdução do significante"(LACAN, O seminário, Livro 9, p. 231). Uma discussão acerca da noção de "mínimo de gozo" é articula em Por que nos identificamos?(PEREZ; STARNINO, Por que nos identificamos?, Cap I.)

51 "Continuo como comecei, pela beleza do gesto" (Holy Motors. Direção: Leos Carax. Imovision, 2012. DVD (1h $55 \mathrm{~min})$ )

52 "O gozo é o que não serve para nada". (LACAN, O seminário, Livro 20, p.10, tradução nossa). Safatle, em uma passagem bastante interessante, nos diz: "Por isso, dirá Lacan em um acento profundamente batailliano, gozo marcado pela perda e pelo dispêndio, gozo marcado por aquilo que parece improdutivo, ao menos a partir da perspectiva do princípio de autoconservação do indivíduo e de suas demandas de amparo. Nesse sentido que podemos dizer que 'na própria repetição há desperdício de gozo' é porque a repetição é gozo de objetos desperdiçados”. (SAFATLE, Sobre Identidade e identificação em Psicanálise, p. 281).

${ }^{53}$ SAFATLE, Sobre Identidade e identificação em Psicanálise, p. 282.

${ }^{54}$ LACAN, O seminário, Livro 20, p.75.

${ }^{55}$ CF. LACAN, O seminário, Livro 9, p.193.
} 
que só pode ser - eu lhes mostrei - a Coisa, que este médium também só pode ser um significante ${ }^{56}$.

Por buscar a Coisa o sujeito se engaja numa direção tortuosa do jogo significante. A nosso ver, a cena final de Holy Motors, mostra, em suma, a alienação estatutária entre 'sujeito-linguagem' e as possibilidades de gozo. Por mais que a realidade em seu caráter contingente apareça como enfadonha, depressiva, tediosa e imprópria para o sujeito, decorrente dos modos com que ele se aliena às cadeias, se está condenado - inclusive para reordená-las - as possibilidades restringidas a materialidade significante.

A cena toda de Holly Motors é a expressão da impossibilidade de não alienação de Oscar a pelo menos uma cadeia e do gozo atravessando todas as possibilidades, aparelhado.

Podemos apontar no âmbito clínico, algo dessa relação sobre as 'possibilidades de gozo’ no limiar do significante. Maria Rita Kehl vai nos lembrar que “o tempo morto do depressivo funciona como refúgio contra a urgência da demanda de gozo do Outro" ${ }^{57}$. Com efeito, a expressão do estado de afetividade intensificado em forma de resposta depressiva é um efeito possível daquilo que de enfadonho aparece como possibilidades de gozo. Pois "o estado depressivo é a atomização do tempo em um conjunto desconexo de instantes desprovidos de tensão e relação" ${ }^{58}$, sendo preciso atomizar o tempo quando na possibilidade significante o gozo é precário, débil em sua radicalidade nominativa, frente àquilo que a demanda Outra reivindica; não se atinge um mínimo de gozo no horizonte da repetição.

Se o sujeito não encontra no horizonte da possibilidade significante, no percurso pulsional trilhado uma saída, o padecimento e o sofrimento encontram guarida. "A depressão descreve muito bem a situação em que me volto contra as escolhas de meu desejo, contra os modelos de minha forma de vida sem, no entanto, ser capaz de articular normatividades alternativas" 59 . Deste modo, acabamos por perpetuar "o vínculo a uma normatividade que reitera continuamente minha impotência em assumir injunções gerais de gozo" 60 . Se como diz Lacan, o "gozo tem que se confrontar com o significante" 61 , o

\footnotetext{
${ }^{56}$ LACAN, O seminário, Livro 9, p.193

${ }^{57} \mathrm{KEHL}$, O tempo e o cão: a atualidade das depressões apud, SAFATLE (Sobre Identidade e identificação em Psicanálise, p.191)

${ }^{58}$ SAFATLE, Sobre Identidade e identificação em Psicanálise, p.191

${ }^{59}$ Ibidem, p.133.

${ }^{60}$ Ibidem, p.134

${ }^{61}$ LACAN, O seminário, Livro 9, p.196.
} 
padecimento é, também, a expressão da debilidade de fruição do mínimo de gozo na dinâmica da repetição. É a legitima expressão de algo sentido fenomenologicamente como um cansaço de si $^{62}$.

\section{O gozo inscrito ao campo da afetividade}

"Direi que o significante se situa no nível da substância gozante"

LACAN, Seminário XX

Com toda essa digressão, almejávamos, em suma, sublinhar exatamente o seguinte ponto: é no "maior ou menor investimento"63, como diz Lacan, no menor dos gestos, que Das Ding é retroativamente convocada, 'miticamente visada'. Voltemos a pergunta que apontamos no início desta seção. O que "está por detrás do sujeito" ${ }^{64}$, como elemento de im-pulsão? O que move o sujeito senão o gozo? O gozo se confronta e atravessa a ordem significante, está por todos os lados, mas não é Um significante; seria algo da ordem da afecção?

Laclau nos diz:

o objeto [tomado por significante] toma a dignidade da Coisa (...). Com isso, chegamos a uma explicação do que significa o investimento radical: tornar um objeto [de modo significante] a corporificarão de uma plenitude mítica. O afeto - isto é, o gozo - é a própria essência do investimento, enquanto seu caráter contingente dá conta do seu componente "radical" da fórmula ${ }^{65}$.

Laclau denomina esse movimento de sustentação ou afirmação de um significante no interior do movimento pulsional de investimento radical, que não é senão a necessária amarração do sujeito a ordem significante. O que isto quer dizer? Que o objeto investido, dito pulsional, é sustentado de modo significante, numa relação fantasmática no interior da linguagem. Não há sustentações de 'puros objetos', de 'objetos pulsionais enquanto tais'. A ordem significante aparelha o objeto dito externo ao nomeá-lo e inseri-lo na relação de linguagem. "Nunca faltam, na superfície, as marcas do próprio significante" 66 , nos diz Lacan. Freud vai cunhar o termo Vorstellungsrepräsentanz - os representantes da pulsão - como um modo de captura do objeto dentro da estrutura das Vorstellungen (representações) ${ }^{67}$.

\footnotetext{
${ }^{62}$ Cf. EHRENBERG La fatigue d'être soi : dépression et société apud SAFATLE (Sobre Identidade e identificação em Psicanálise, p.215)

${ }^{63}$ LACAN, O seminário, Livro 7, p.135, p.127.

${ }^{64}$ Ibidem

${ }^{65}$ LACLAU, A Razão Populista, p.179

${ }^{66}$ LACAN, O seminário, Livro 14, p. 86.

${ }^{67}$ Ver também nota 36 deste artigo.
} 
A ação de significar - os significantes - 'tocam' o próprio objeto, digamos assim. Lacan aponta esse 'encontro íntimo' do interno com o externo de êxtimidade: êxtimidade, êxtimo, são neologismos que surgem para articular a paradoxal conjugação do íntimo com o externo, -exterioridade intima ${ }^{68}$. No Seminário IV - A Relação Objeto, Lacan é bastante direto quanto a este ponto, também. Ele nos diz: “Tudo o que Freud desenvolve consiste em mostrar o efeito de aniquilamento, o caráter realmente destruidor, disruptor do jogo do significante com relação àquilo a que se pode chamar a existência do real. Jogando com o significante o homem põe em causa a todo instante seu mundo, até a sua raiz" ${ }^{69}$.

Outro ponto fundamental trazido por Laclau no trecho acima é a aproximação entre afecção e a dimensão do gozo, inscrita ao discurso e a linguagem. Isso é algo que sinteticamente pode ser pensado como a articulação teórica de essencialmente três seminários lacanianos: o que é desenvolvido no Seminário VII, apontando a diferença entre Das Ding e os objetos parciais da sublimação, afirmando que por sublimação se entende a promoção de um objeto ordinário ao "estatuto de dignidade da coisa" 70, como já abordamos aqui antes. Porque para fundamentar que o gozo é um afeto, Laclau vai articular a noção de gozo como usufruto na relação com Das Ding, no investimento radical em objetos parciais. Usufruto esse que se consuma no investimento radical-gozo que se reduz a ser em uma instância negativa, aquilo que não serve a nada, que aparece no Seminário $X X$ - incondicionado e contingente, ainda que não indiferente à relação com o significante, senão não faria sentido algum o termo usufruto.

Tudo pode ser tomado por um gozo, não há finalidade a priori. A noção de investimento radical em Laclau elide a Coisa e eleva o parcial e ordinário ao estatuto "de uma parte que se torna o todo". Como nos diz Laclau, "o objeto do investimento pode ser contingente, mas certamente não é indiferente, não pode ser mudado à vontade" ${ }^{1}$. É nesse sentido que a repetição ganha o caráter de gozo parcial através dos significantes que se repetem nas cadeias. "Não existe gozo alcançável a não ser através de um investimento radical em um objeto a (...) o gozo não está perdido [devido a interdição de Das Ding], isso ocorre porque traços dele permanecem nos objetos parciais"72. Deste modo, a própria essência do movimento, do investimento repetitivo, na íntima relação com o significante, sela o destino do gozo.

Desse modo, objeto parcial torna-se o princípio estruturante de toda cena:

O desenvolvimento do conceito de Vorstellungsrepräsentanz [aproximado por Lacan da noção de significante como mostramos] parece cortar o

\footnotetext{
${ }^{68}$ Lacan utiliza tal terminologia, dentre outros seminários, no SVII (Lição XI) e SXVI (lição XVI). (Cf. STARNINO, Entre o couro e a carne, p. 17 e 29).

${ }^{69}$ LACAN, O seminário, Livro 4, p. 301.

${ }^{70}$ LACAN, O seminário, Livro 7, p. 137.

${ }^{71}$ LACLAU, A Razão Populista, p. 179

${ }^{72}$ Ibidem. Disso segue também a firmação de Lacan de que “o objeto a é o nucleio elaborável do gozo”. (Cf. LACAN, O seminário, Livro 7 , Lição $V$ - O campo lacaniano).
} 
componente Ding do complexo Nebenmensch em duas partes, em das Ding e em Vorstellungsrepräsentanz, embora das Ding já não seja concebido como objeto numênico, sendo mantido unicamente pela descrição do Vorstellungsrepräsentanz como algo parcial. De acordo com essa teoria, fica claro que, quando este objeto parcial chega à cena, ele bloqueia o caminho que a conduz à antiga concepção de das Ding, que agora não passa de uma ilusão retrospectiva ${ }^{73}$.

Finalmente, conforme tentamos ilustrar nas figuras abaixo, se o gozo ( $\mathrm{J}$ ) não é da ordem da afecção e fundamentalmente efeito desse processo de investimento - na esteira do que nos mostra Lacan, Laclau e Copjec - como essência do investimento que compõem a relação entre sujeito, arco pulsional, que circula, marca, trilha os objetos parciais para depois ocorrer a repetição do mesmo movimento, atravessando a ordem significante, o que seria então? Não é o vivente em sua situação ordinária de linguagem e discurso que goza, se afeta, se expõem ao gozo? Como diz Lacan, "nada é mais candente do que aquilo que, do discurso, faz referência ao gozo. O discurso toca nisso sem cessar"74.

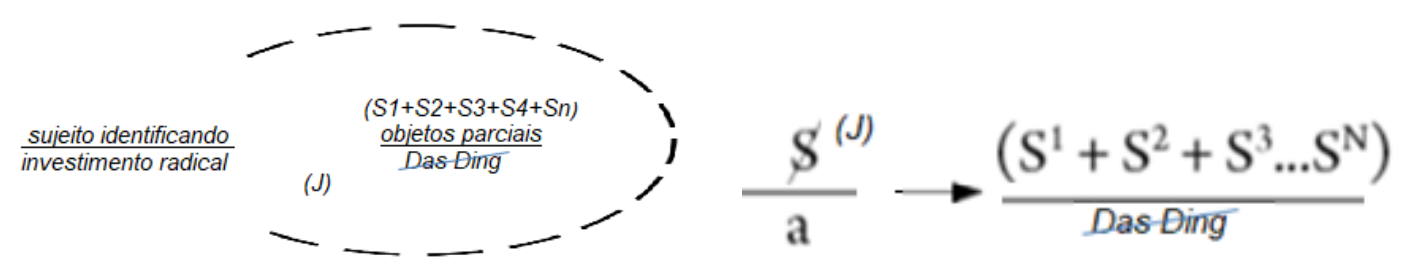

Figura 6: O gozo, o discurso identitário e Das Ding

O gozo é a própria essência e ao mesmo tempo efeito do investimento contingente nas cadeias significantes, através das pulsões parciais que transformam o próprio arco pulsional em pleno “campo de discursividade”. Nisso se funda a ampliação do campo discursivo operada na Teoria do Discurso de Ernesto Laclau, não só relacionando o discurso às áreas da fala ou escrita, mas a todo gesto, ação: inscrições significantes. Isso nos leva a feliz expressão de Milner de que "o significante é ação, como o próprio nome diz"75. Ação na diferença.

Laclau, em sua interpretação de Lacan, coloca o afeto, isto é, o gozo, no limiar da constituição discursiva; como o cimento camuflado que 'substenta' os tijolos no interior de uma parede tortuosa. Disso se compõem as diversas modalidades de gozo descritas por Lacan - gozo perverso; gozo feminino; gozo fálico; mais-gozar, entre outros - todas elas visam distinguir "meios de gozo"76; modos diferenciais de trilhar o arco pulsional na

\footnotetext{
${ }^{73}$ COPJEC, Imagine there's no woman apud LACLAU, A Razão Populista, p.176.

${ }^{74}$ LACAN, O seminário, Livro 17, p.66

${ }^{75}$ MILNER, Linguística e psicanálise, p. 9

${ }^{76}$ Expressão utilizada por Lacan no SXVII (p.66)
} 
direção dos objetos parciais, no modus operandi em que se repetem as cadeias significantes.

\section{Conclusão}

Conforme procuramos demonstrar, a Psicanálise e sua consequente subversão do campo da linguagem e discurso se organiza como um pilar teórico nos trabalhos de Ernesto Laclau. Podemos afirmar que o filosofo político e teórico do discurso avançou epistemologicamente nos limites e consequências do político, possibilitando formulações abrangentes, sobretudo a partir das noções de significante, linguagem, gozo e Real (em sentido lacaniano). Essa incorporação de pressupostos psicanalíticos promove, em sentido amplo, o maior instrumento de sua Filosofia Política, a saber, sua potente Teoria do Discurso; trazendo inovação nos estudos sobre a constituição das identidades coletivas, o fenômeno do populismo, os estudos de hegemonia e ideologia, além de reinterpretações sobre marxismo, sociedade, política, algo que, por questões obvias, não é o escopo desse trabalho adentrar ${ }^{77}$.

Uma questão central nos traz Mendonça e Lopes na apresentação da versão em português de $A$ Razão populista: "Mas o que há de realmente novo na formulação desenvolvida pelo autor? Fundamentalmente, o desenvolvimento de uma teoria geral capaz de explicar a ocorrência de uma lógica política especifica: a da formação de identidades coletivas"78. Justamente, no interior dessa "teoria geral" unificada por matrizes epistemológicas distintas é onde podemos inscrever o ponto de maior avanço epistemológico concernentes a intersecção com o campo psicanalítico - e ao mesmo tempo de maior complexidade teórica -, trata-se do entroncamento entre discurso, gozo e campo pulsional, sendo o gozo pensado pelo autor como da ordem da afecção. A partir de quatro proposições ampliadas, podemos extrair a síntese do que procuramos demonstrar nesse artigo:

(a) É partir da implicação da noção de significante em Lacan que Ernesto Laclau tece sua noção de discurso enquanto "palavras ou ações, que podem ser sucessivos ou simultâneos”79: isto é a própria ‘ação significante’ em significar na pura diferença.

(b) Na construção discursiva, "os elementos não preexistem ao complexo relacional, mas se constituem através dele" ${ }^{80}$ : na ação significante, em remessas infindáveis de sentido.

\footnotetext{
${ }^{77}$ Como já dito, podemos apontar A Razão populista, uma espécie de síntese dos trabalhos anteriores, como a principal obra de Ernesto Laclau onde o autor aprofunda sua abrangente e inovadora filosofia política.

${ }^{78}$ LACLAU, A Razão Populista, p.11

${ }^{79}$ Ibidem, p.116.
} 
(c) Desse modo, "aquilo que é verdadeiro em relação à linguagem concebida em estrito sensu é também verdadeiro em relação a qualquer elemento significativo" ${ }^{81}$. O discurso assim ampliado torna-se "essa espécie de laço social", como afirma Lacan, em contornos de "cadeias equivalenciais", como indica Laclau, que encontramos nas mais diversas construções discursivas. Amplia-se, portanto, o alcance da análise do discurso para "além das áreas da fala ou escrita”.

(d) De modo consubstancial às relações de linguagem e discurso temos circuitos afetivos, também contingentes, que se afirmam e se reconfiguram na cadeia discursiva, numa verdadeira dialética de compromisso mútuo ${ }^{82}$. O gozo aparece como "substancial" daí resulta a expressão "substância gozante" de Lacan ${ }^{83}$ - a toda operação discursiva, em modos diferenciais de trilhar o arco pulsional na direção dos objetos parciais, no modus operandi em que se repetem as cadeias significantes.

\section{Referências}

COPJEC, J. (2004) Imagine there's no woman: Ethics and Sublimation, Cambridge: MIT Press.

DUNKER, C. I. L. (2017) Uma via indireta para a abordagem do afeto: libido, gozo, pulsão escópica, Tempo Psicanalítico, Rio de Janeiro, v. 49.1, p. 9-36.

Holy Motors. Direção: Leos Carax. Imovision, 2012. DVD (1h 55 min).

EHRENBERG, Alain (2011) La fatigue d'être soi : dépression et société, Paris : Fayard.

HOWARTH, D. (2000) Discourse, Buckingham: Open University Press.

JARDIM, Ricardo. (2013) Energética e Hermenêutica: "o Problema epistemológico do Freudismo” discutido por Paul Ricoeur - PROMETEUS.

KEHL, Maria R. (2009) O tempo e o cão: a atualidade das depressões, São Paulo: Boitempo. LACAN, J. (1955-56/1977). O Seminário Psicoses. Livro 3. Rio de Janeiro: Zahar Editores. LACAN, J. (1956-57/1995) O seminário, Livro 4 - A relação de objeto - Rio de Janeiro: Jorge Zahar.

LACAN, J. (1959-60/2008) O seminário, Livro 7 - A Ética da Psicanálise. Rio de Janeiro: Jorge Zahar.

\footnotetext{
${ }^{80}$ Ibidem.

${ }^{81}$ Ibidem.

${ }^{82}$ Sobre uma discussão acerca da noção de afeto em Lacan ver STARNINO, Les affects sont effects: Para pensar a noção de afeto em Jacques Lacan

83 "Direi que o significante se situa no nível da substancia gozante" (LACAN, O seminário, Livro 20, p. 35.
} 
LACAN, J. (1961-62/2003) O seminário, Livro 9 - A identificação. Recife, : Centro de estudos Freudianos do Recife, (não oficial).

LACAN, J. (1962-63/2005) O seminário, Livro 10 - A Angústia. Rio de Janeiro: Jorge Zahar.

LACAN, J. (1964/1988) O seminário, Livro 11 - Os quatro conceitos fundamentais da Psicanálise. Rio de Janeiro: Jorge Zahar.

LACAN, J. 1966-67/2008) O seminário, Livro 14 - A Lógica do Fantasma. Recife, : Centro de estudos Freudianos do Recife (não oficial).

LACAN, J. (1967-68/2008) O seminário, Livro 16 - De um Outro ao outro, Rio de Janeiro: Jorge Zahar, 2008

LACAN, J. (1969-70/1991) O seminário, Livro 17 - O Avesso da Psicanálise, Rio de Janeiro: Jorge Zahar.

LACAN, J. (1972-73/1989) O seminário, Livro 20 - Mais ainda - Rio de Janeiro: Jorge Zahar.

LACAN, J. (1993) Televisão - Rio de Janeiro: Jorge Zahar.

LACAN, J. (1972/2017) Conférence de Louvain, La Cause Du Désir, (N 96), p. 7-30

LACLAU, E. (2013) A razão Populista. São Paulo: Três Estrelas.

LACLAU, E. (2014) El discurso, lo político y la dimensión ontológica: Una entrevista con Ernesto Laclau: Revista de la Academia/ISSN 0719-6318 Volumen 22/Primavera 2016 (Publicado originalmente en Distinktion. Journal of Social Theory, Vol. 15, ISS 3, pp. 255262. Tradução de José Fernando García)

LACLAU, E. (2014b) Los fundamentos retóricos de la sociedad, Ciudad Autónoma de Buenos Aires: Fondo de Cultura Económica

LACLAU, E. MOUFFE, C. (1987) Hegemonía y estrategia socialista. Hacia una radicalización de la democracia. Madrid: Siglo XXI España.

MANSET, G. (1991) Revivre, Paroles et Musique: France (musica).

MILNER, J. C. - (1992/2010) Linguística e Psicanálise (Linguistics and Psychoanalysis). Estud. Lacan.[online] , vol.3, n.4. (Publicado originalmente nas versões online e em papel da Encylopædia Universalis. [cf. Corpus, Paris: Encylopædia Universalis France S. A., n. 13, pp. 858-62, 1992]. Traduzido por Paulo Sérgio de Souza Jr, IEL-UNICAMP)

PEREZ D. O; STARNINO, A. (org) (2018) Por que nos identificamos? Curitiba: CRV.

RICOEUR, P. (1977) De l'interprétation, essai sur Freud. Paris: Seuil, 1965. Em português: Da interpretação, ensaio sobre Freud, Rio de Janeiro: Imago

RICOEUR, P. (1969) Le conflit des interprétations: essais d’herméneutique . Paris: Seuil, 
SAFATLE, Vladimir (2016). O circuito dos afetos: Corpos politiciso, desamparo e o fim do indivíduo - São Paulo: Editora Cosac Nayfy.

SOLER, C. (2004) Ce que Lacan disait des femmes. Paris : Éditions du Champ Lacanien, 2004.

SOLER, C. Les affects lacaniens - Paris: PUF - 2016.,

STARNINO, A. (2016) Sobre Identidade e identificação em Psicanálise: um estudo a partir do Seminário IX de Jacques Lacan- Curitiba/UFPR: Revista Dois Pontos , 2016

STARNINO, A. (2018) Entre o couro e a carne: Jacques Lacan e questão da identidade e identificação. Dissertação (Filosofia) - UNICAMP. Campinas.

STARNINO, A. 2019) Les affects sont effects:Para pensar a noção de afeto em Jacques Lacan. Modernos \& Contemporâneos, v. 3, p. 44-65

STAVRAKAKIS, Y. (2010) Discourse, affect, jouissance: Psychoanalysis, Political Theory and Artistic Practices, Istanbul: Art \& Desire Seminars, June.

VALAS, P. (2011) As dimensões do gozo: Do mito da pulsão a deriva do gozo, Rio de Janeiro: Jorge Zahar Ed. 